\title{
Multiple schwannomas of the digital nerves and superficial radial nerve: two unusual cases of segmental schwannomatosis
}

\author{
Jerzy Gosk ${ }^{1}$, Olga Gutkowska ${ }^{1}$, Sebastian Kuliński ${ }^{1}$, Maciej Urban ${ }^{1}$, Agnieszka Hałoń ${ }^{2}$ \\ ${ }^{1}$ Department of Traumatology, Clinic of Traumatology and Hand Surgery, Wroclaw Medical University, Wroclaw, ${ }^{2}$ Division \\ of Pathomorphology and Oncological Cytology, Wroclaw Medical University, Wroclaw, Poland
}

\begin{abstract}
Two cases of segmental sporadic schwannomatosis characterized by unusual location of multiple schwannomas in digital nerves (case 1) and the superficial radial nerve (case 2) are described in this paper. In the first of the described cases, 6 tumours located at the base of the middle finger and in its distal portion were excised from both digital nerves. In the second case, 3 tumours located in the proximal 1/3 and halfway down the forearm were removed from the superficial radial nerve. In both cases, symptoms such as palpable tumour mass, pain, paraesthesias, and positive Tinel-Hoffman sign resolved after operative treatment. Final diagnoses were made based on histopathological examination results. In the second of the described cases, the largest of the excised lesions had features enabling diagnosis of a rare tumour type - ancient schwannoma.
\end{abstract}

Key words: schwannomatosis, multiple neurilemmomas, ancient schwannoma, superficial radial nerve, digital nerve.

\section{Introduction}

Schwannomas are benign neoplasms derived from Schwann cells. They mostly occur as solitary tumours $[6,7,25]$. Multiple schwannomas developing in individual nerves are very rare $[14,24,29,33,35]$. Their presence may be one of the symptoms indicative of neurofibromatosis type 2 or schwannomatosis $[5,13,25]$. In material presented by Ogose et al. multiple schwannomas were found in $4.6 \%$ of all patients treated for schwannoma [25]. Qualification for surgical treatment of multiple schwannomas is controversial. Some authors highlight elevated risk of iatrogenic damage to the nerve during tumour excision [24]. Advocates of surgical treatment raise the possibility of development of multilevel compression neuropathy as a result of the growth of tumours
[5]. It is obvious that only symptomatic tumours are qualified for excision [5].

\section{Case report}

\section{Case 1}

A 26-year-old woman was admitted to our ward for surgical treatment of multiple nodules located in the middle finger of her left hand. The nodules began to be palpable 6 years earlier. There was no history of significant trauma or inflammation of the left hand. The patient reported pain that increased when pressure was applied on the nodules and with finger movements. Paraesthesias were present in the fingerpad of the patient's third finger.

On ultrasound examination performed on 1.04.2011 a polycyclic lesion consisting of 3 nodules was seen 
along the proper digital nerve on the radial side of the third finger. The lesion originated at the level of the metacarpophalangeal joint and continued for about $33 \mathrm{~mm}$. Consecutive individual nodules were 7.5, 11 and $9 \mathrm{~mm}$ in diameter, going proximally. In the same nerve, presence of another solitary nodule with a diameter of $3.6 \mathrm{~mm}$ located $3 \mathrm{~mm}$ distally from the proximal interphalangeal joint was detected. Presence of another nodule measuring $4.5 \mathrm{~mm}$ in diameter was revealed in the proper digital nerve on the ulnar side near the distal interphalangeal joint. Magnetic resonance imaging (MRI) examination (Siemes Essenza 1.5T) performed on 25.03.2013 showed a polycyclic lesion about $36 \mathrm{~mm}$ long derived from the proper digital nerve on the radial side of the third finger. Presence of another tumour measuring $5 \mathrm{~mm}$ in diameter and located in the proper digital nerve on the ulnar side of the distal portion of the middle phalanx was also revealed. The tumours showed significant enhancement after administration of contrast agent - Figure 1 .
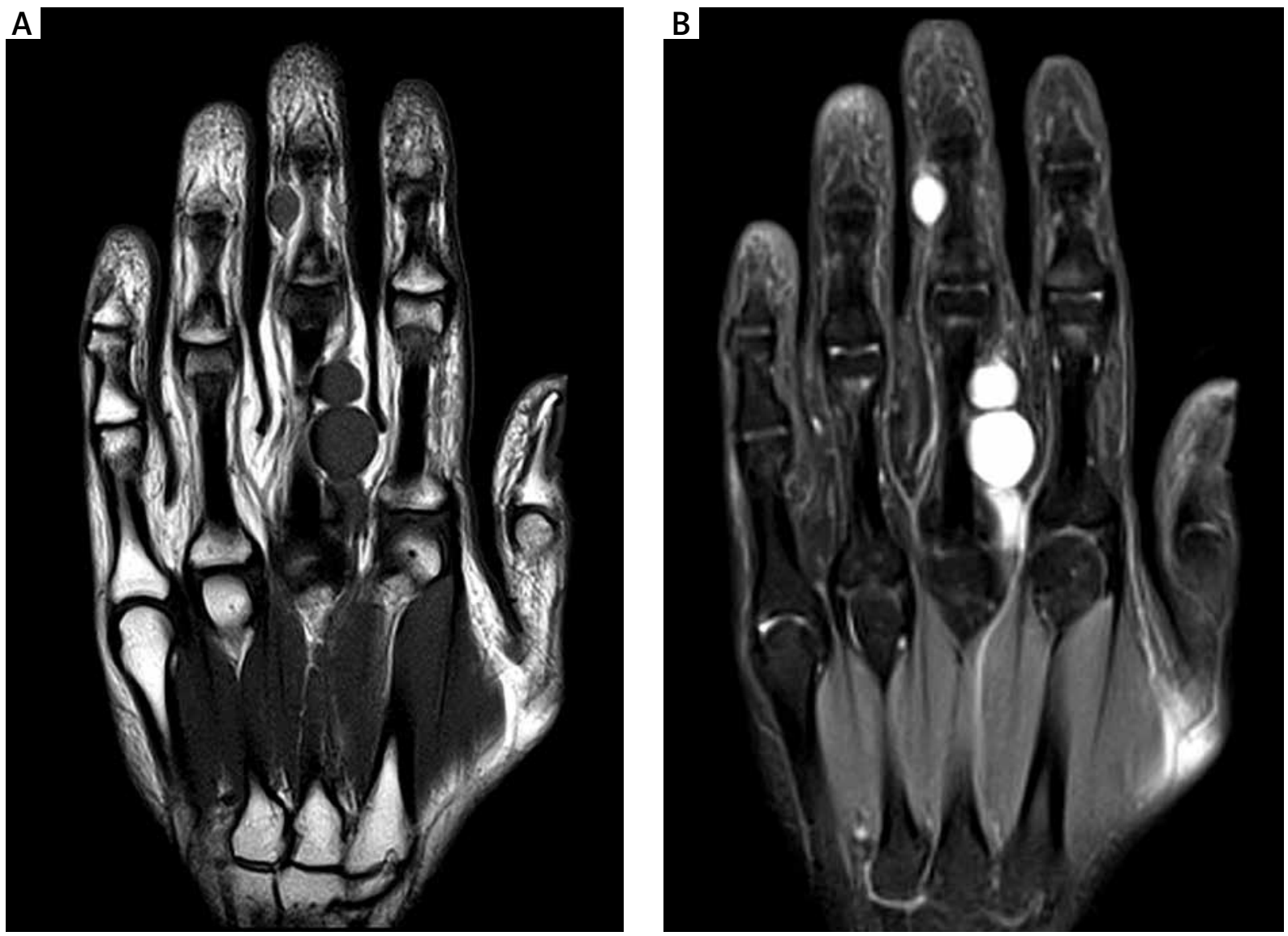

Fig. 1. Magnetic resonance imaging examination results. A) Visualization of tumours located in both digital nerves of the third finger. B) Contrast enhancement of the tumours. 

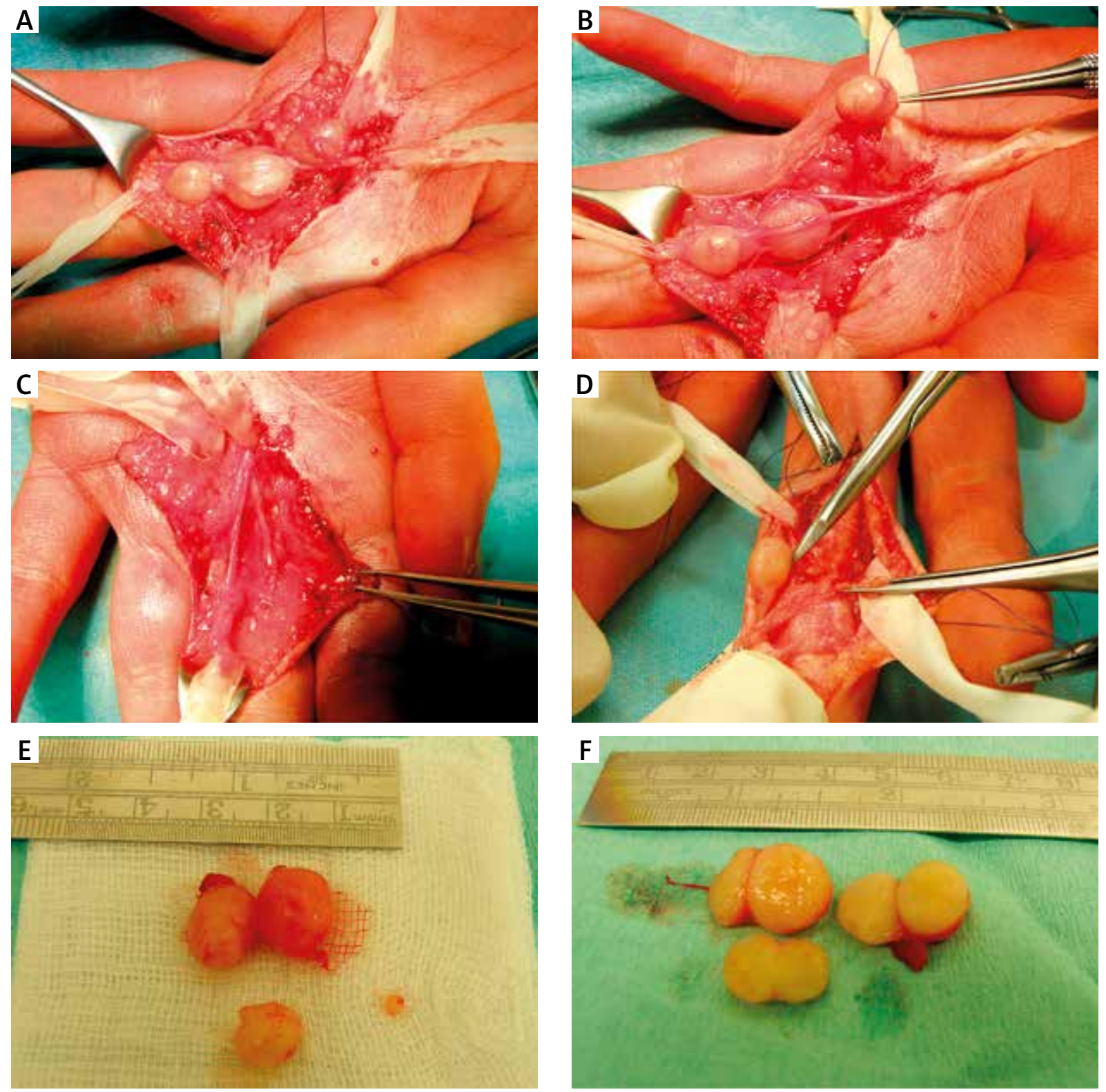

Fig. 2. Intraoperative view: A) tumours in the course of radial digital nerve, B) view of operative field after removal of one of the tumours, C) radial digital nerve after resection of the tumours, D) tumour of ulnar digital nerve, E) appearance of the tumours after removal from radial digital nerve, F) cross-section of the tumours.

tion performed on 30.09.2013 a nodule located in the proper digital nerve on the ulnar side at the level of the distal interphalangeal joint and another nodule located on the opposite side at the level of the base of the middle phalanx were removed. The nodules were 5 and $3 \mathrm{~mm}$ in diameter - Figure 2 . Surgical treatment was divided into two stages in order to avoid vast dissection of tissues of the third finger. Both operations were performed using tourniquet ischemia, microsurgical tools and an operating microscope. All nodules were excised without damage to the fascicular structure of nerves.

On postoperative histopathological examination all tumours had the same histopathological pattern - neurilemmoma Antoni A (sample numbers: 26895 from 17.05.2013 and 31909 from 18.10.2013). Im- 

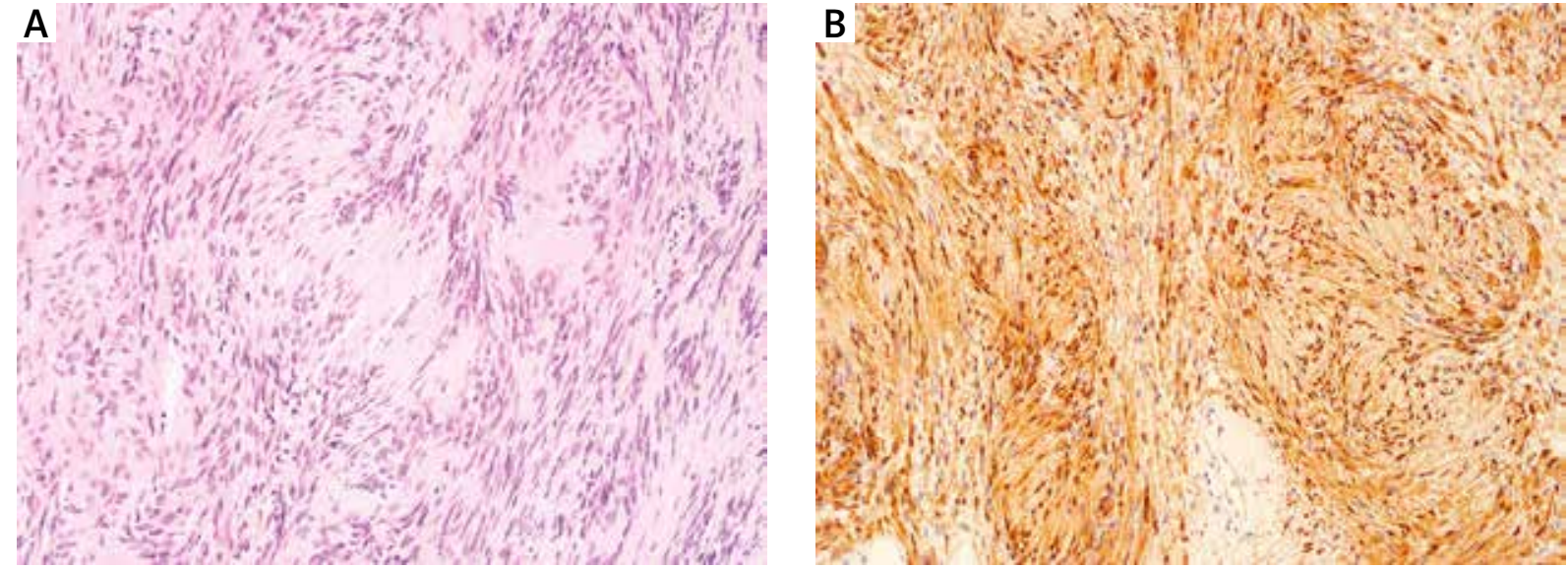

Fig. 3. Histopathological examination results: A) neurilemmoma Antoni A, H\&E stain, $\times 100$ magnification; B) immunohistochemical expression of S-100 protein in Schwann cell.

munohistochemical analysis showed positive reaction against S-100 protein - Figure 3.

In the early postoperative stage no worsening of function of digital nerves was observed. The patient is under ambulatory surveillance. In the long-term postoperative course no signs of recurrence of nodules were observed. Pain and paraesthesias in the fingerpad of the third finger resolved. Tinel-Hoffman sign is currently negative. The postoperative scar formed at the base of the third finger slightly limits full extension of the finger.

\section{Case 2}

A 22-year-old woman was admitted to our ward for operative treatment of tumours located on her left forearm. The tumours first appeared about two years earlier. The patient had no history of trauma to the affected area. In anamnesis, the patient reported pain elicited by applying pressure to the tumour mass and after overstraining the limb as well as presence of paraesthesias in the dorsum of the 1 st and 2nd fingers of her left hand. On ultrasound examination performed on 19.07.2013 presence of 2 tumours in the course of the superficial branch of the radial nerve was detected. The proximal lesion measuring $23 \times 16 \times 36 \mathrm{~mm}$ was located about $2 \mathrm{~cm}$ from the site of division of the major trunk of the radial nerve. This tumour was well encapsulated, located under the epineurium and caused displacement of nerve fascicles. Matrix of the tumour was heterogeneous with numerous fluid collections. The peripheral lesion had the dimensions $17 \times 7 \times$ $\times 5 \mathrm{~mm}$ and its matrix was homogeneous. On MRI examination performed on 11.04.2013, presence of two nodules differing in size located in the superficial radial nerve was detected. The larger of them, measuring $37 \times 20 \times 18 \mathrm{~mm}$, was located about $3 \mathrm{~cm}$ from the cubital joint. The other one was located peripherally, about $9 \mathrm{~cm}$ from the cubital joint, and measured $7 \times 6 \times 16 \mathrm{~mm}$. The tumours showed heterogeneous contrast enhancement - Figure 4 .

Presence of a palpable mass of two tumours located in the proximal $1 / 3$ and halfway down the forearm was confirmed on clinical examination. Pain was triggered by applying pressure to the tumours. On percussion of the tumours Hoffman-Tinel sign was elicited, and the patient reported paraesthesias of the dorsal side of the 1st and 2nd finger as well as radial aspect of the dorsum of the hand. Examination of superficial sensory function in this region did not reveal significant impairment compared to the opposite side. No muscle atrophy in the hand and forearm was observed. The patient was scheduled for surgical removal of the tumours. The procedure was performed on 15.10.2013 from a single incision in the proximal $1 / 3$ and halfway down the forearm. The operation was performed using tourniquet ischemia and an operating microscope. Two tumours measuring $32 \times 20 \times 15 \mathrm{~mm}$ and $12 \times 8 \times$ $\times 5 \mathrm{~mm}$ were excised with transection of one fascicle - Figures 5 and 6 . In the peripheral portion of the superficial radial nerve, presence of a third nodule, previously not visible on imaging scans, was detected. This small nodule, measuring $3 \mathrm{~mm}$ in diameter, was removed without damage to the fascicular structure. The cross-section of the largest of the excised 


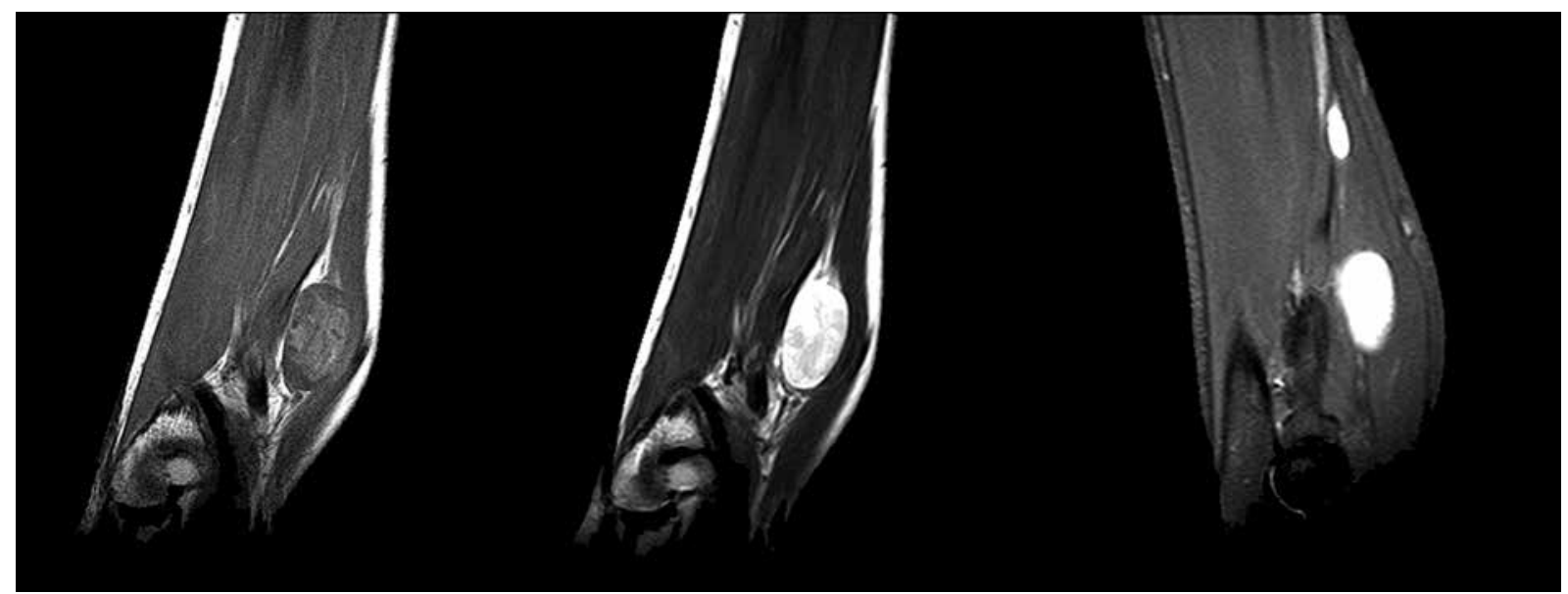

Fig. 4. Magnetic resonance imaging examination results: visualization of tumours in the course of the superficial radial nerve.
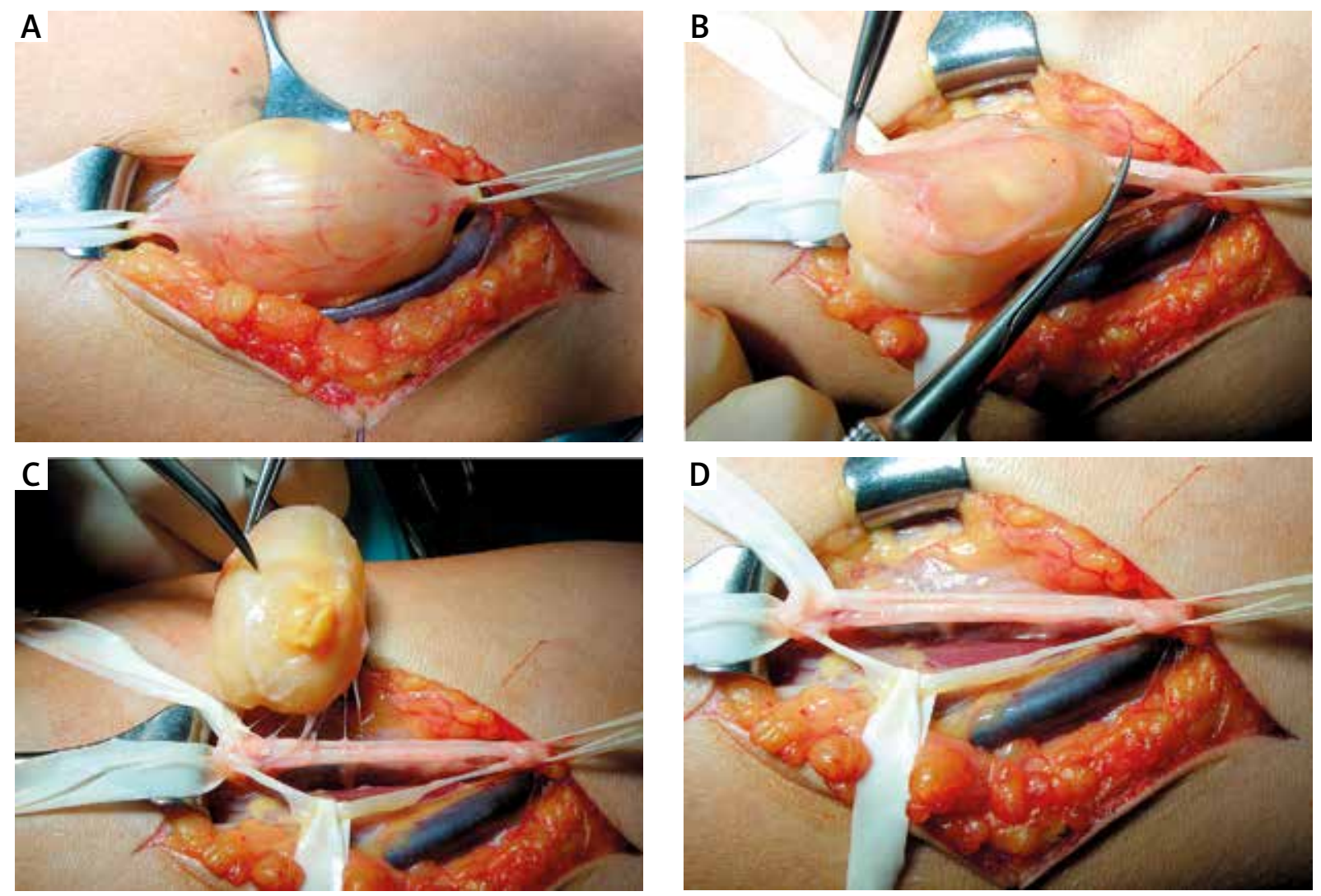

Fig. 5. Intraoperative view: A) larger tumour of superficial radial nerve in proximal third of the forearm, B) transection of the single fascicle entering the tumour, C) removal of the tumour from the superficial radial nerve, D) appearance of the superficial radial nerve after tumour resection.

tumours (located in the proximal forearm) revealed macroscopic features of cystic degeneration with a leak of gelatinous, yellowish liquid and presence of tiny beige nodules - Figure 7 . On histopathological examination this tumour had characteristics enabling diagnosis of ancient schwannoma: microcyst and cyst formation, perivascular hyalinisation, nuclear atypia without mitotic figures (sample number - 32456 

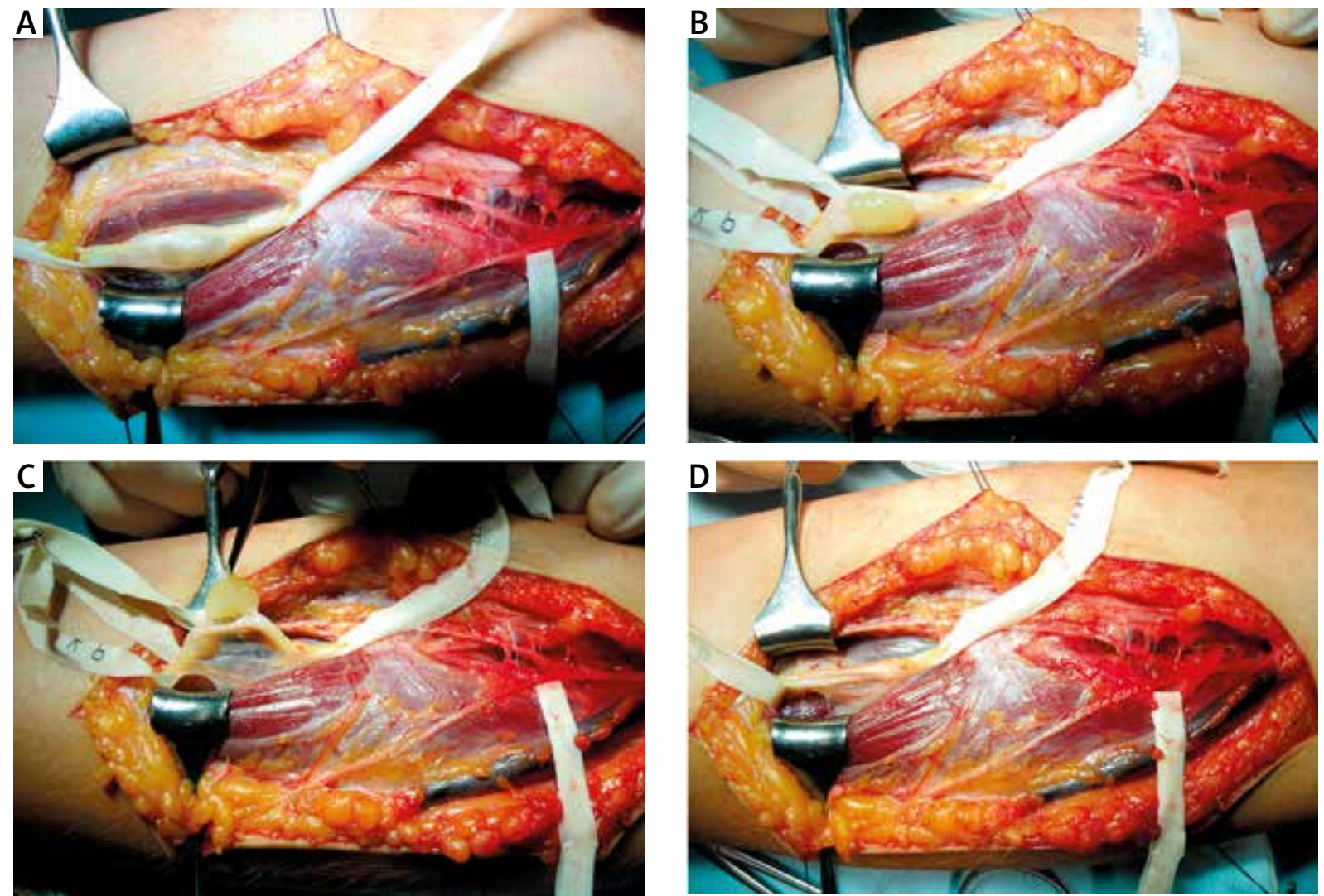

Fig. 6. Intraoperative view: A) smaller tumour of the superficial radial nerve located halfway down the forearm, B) dissection of the tumour, C) removal of the tumour, D) appearance of the superficial radial nerve after resection of the tumour.
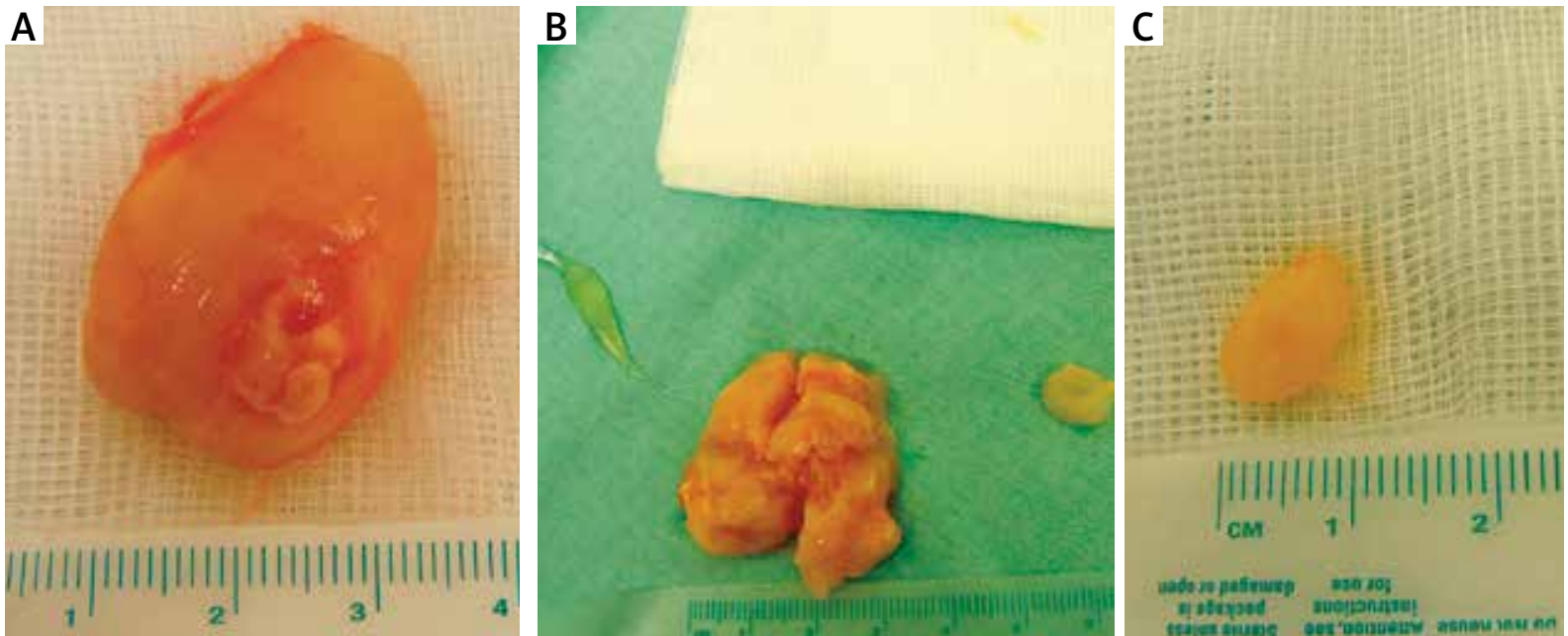

Fig. 7. Postoperative view: A) larger tumour after removal, B) both tumours after removal (cross-section of the larger tumour with leak of gelatinous substance), C) smaller tumour after removal. 
from 24.10.2013) - Figure 8. The other two tumours had a histological pattern of classical schwannoma. The postoperative course was uncomplicated. No symptoms of recurrence of tumours were detected at follow-up examinations, and pain and paraesthesias resolved. Tinel-Hoffman sign is negative.

\section{Discussion}

Location of solitary schwannomas in the hand and fingers is rare $[8,27]$. Cases of multiple schwannomas in this region are of great rarity [41]. In material presented by Rockwell et al. schwannomas located in the hand and wrist constituted $7.5 \%$ of all schwannomas. The most frequent site of origin in material presented by authors mentioned above were proper digital nerves (52\%) and common digital nerves (19\%). Multiple tumours were detected in two female patients described by these authors; they derived, however, from separate nerves. Rockwell et al. did not describe any tumours located peripherally to the proximal interphalangeal joint [27]. Peripheral location of schwannomas in fingers is a subject of casuistic reports [15,32]. Kilic et al. presented a case of a painful solitary schwannoma located in middle and distal phalanges of the $3^{\text {rd }}$ finger of the left hand [15]. Takeuchi et al. described a solitary schwannoma located in the distal phalanx of the $4^{\text {th }}$ finger of the right hand [32]. The case presented in this work is unique due to the fact that schwannomas developed in both digital nerves and occurred simultaneously proximally and distally to the proximal interphalangeal joint.

In the second of the described cases the tumours were located in the superficial radial nerve. The super- ficial radial nerve is a sensory branch of the radial nerve that provides cutaneous innervation to the dorsal aspect of the hand, including the thumb, index finger and the radial aspect of the long finger [23]. The superficial radial nerve might be compressed or injured at various anatomical sites along its course in the forearm [26]. Cases of external compression by an osteochondroma, lipoma or ganglion cyst $[19,26,36,40]$ as well as development of tumours such as nerve sheath ganglion, lipofibroma and plasmocytoma intraneurally $[4,11,30]$ have been described. The first case of schwannoma located in the superficial radial nerve was described by Visser in 2009 [37]. The tumour was located $7 \mathrm{~cm}$ above the styloid process of the radius [37]. Other cases of solitary schwannoma were presented by Kim et al. and Tang et al. and were located halfway down the forearm and in the wrist, respectively [16,34]. Compression of the superficial radial nerve occurring at the proximal third of the forearm is unusual $[26,36]$. In our material the largest tumour was located in the proximal third of the forearm and 2 smaller ones halfway down its length. Tanabe et al. presented a case of a 38-yearold woman with multiple schwannomas (5 tumours) in the radial nerve (arm) and posterior interosseous nerve (forearm) [33]. According to the authors it was the first documented description of multiple schwannomas in the radial nerve and its motor branch [33]. To the best of our knowledge, multiple schwannomas of the superficial radial nerve have not previously been described.

Cystic degeneration of the largest tumour located in the superficial radial nerve (case 2), which was detected both on imaging scans and intraoperatively,

Table I. Criteria for diagnosis of schwannomatosis

\begin{tabular}{|c|c|c|}
\hline Schwannomatosis* & & Diagnostic criteria \\
\hline \multirow[t]{2}{*}{ Definite } & & $\begin{array}{l}\text { Age }>30 \text { years and two or more non-intradermal schwannomas (at least one with histological con- } \\
\text { firmation) }\end{array}$ \\
\hline & or & One schwannoma confirmed with histology and a first-degree relative who meets the above criteria \\
\hline \multirow[t]{3}{*}{ Possible } & & $\begin{array}{l}\text { Age }<30 \text { years and two or more non-intradermal schwannomas (at least one with histological confir- } \\
\text { mation) }\end{array}$ \\
\hline & or & $\begin{array}{l}\text { Age }>45 \text { years and no symptoms of eighth cranial nerve dysfunction and two or more non-intradermal } \\
\text { schwannomas (at least one with histological confirmation) }\end{array}$ \\
\hline & or & $\begin{array}{l}\text { Radiographic evidence of a schwannoma and a first-degree relative who meets the criteria for defi- } \\
\text { nite schwannomatosis }\end{array}$ \\
\hline Segmental & & $\begin{array}{l}\text { Meets criteria for definite or possible schwannomatosis but limited to one limb or five or fewer } \\
\text { contiguous segments of the spine }\end{array}$ \\
\hline
\end{tabular}

*Individuals must not fulfil the criteria for NF2 or have any of the following: Vestibular schwannoma on MRI, constitutional NF2 mutation, or a first degree relative with NF2. 
prompted us to perform detailed histopathological examination. Ancient schwannoma was diagnosed on the basis of the following features: microcyst and cyst formation, perivascular hyalinisation and
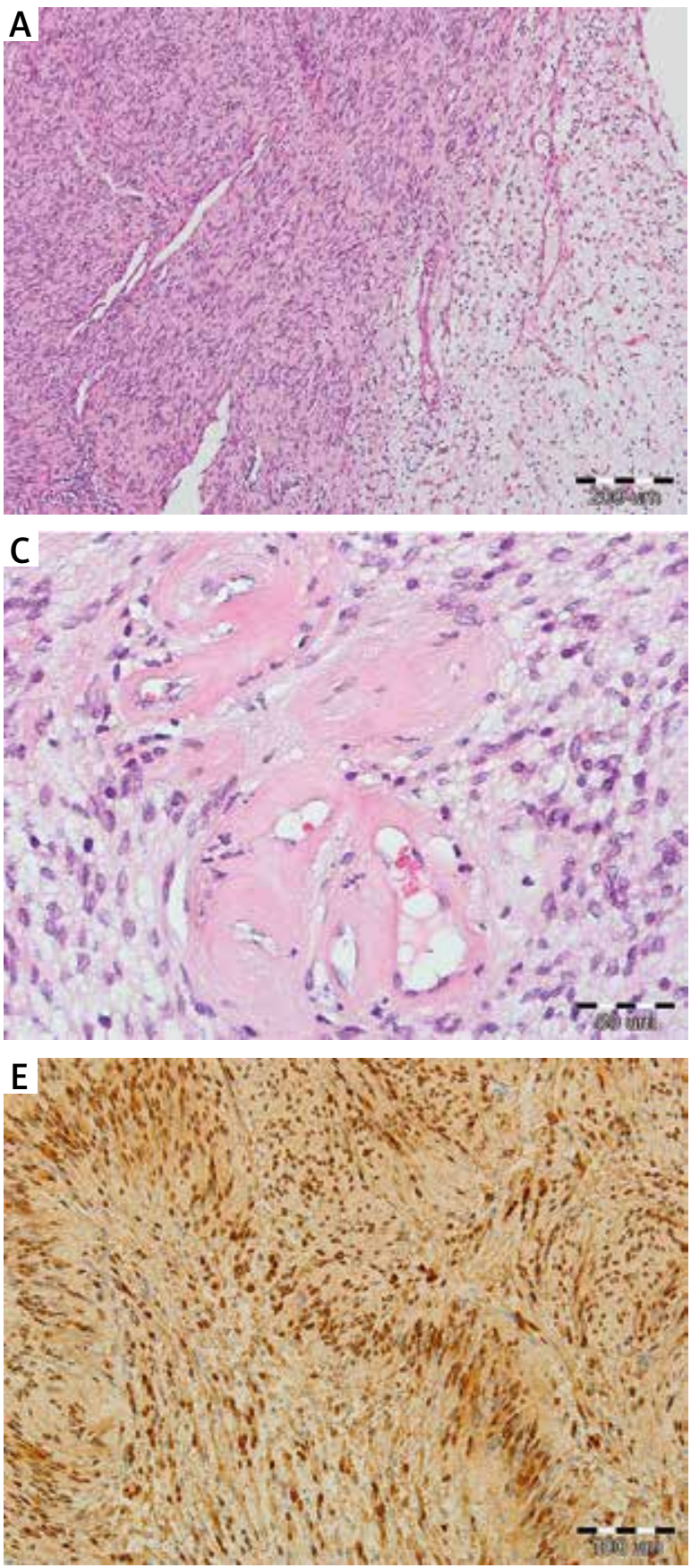

nuclear atypia. In our histopathological samples no calcification or hemorrhagic areas were detected. However, these features are not always present. Isobe et al. observed calcification only in two out of
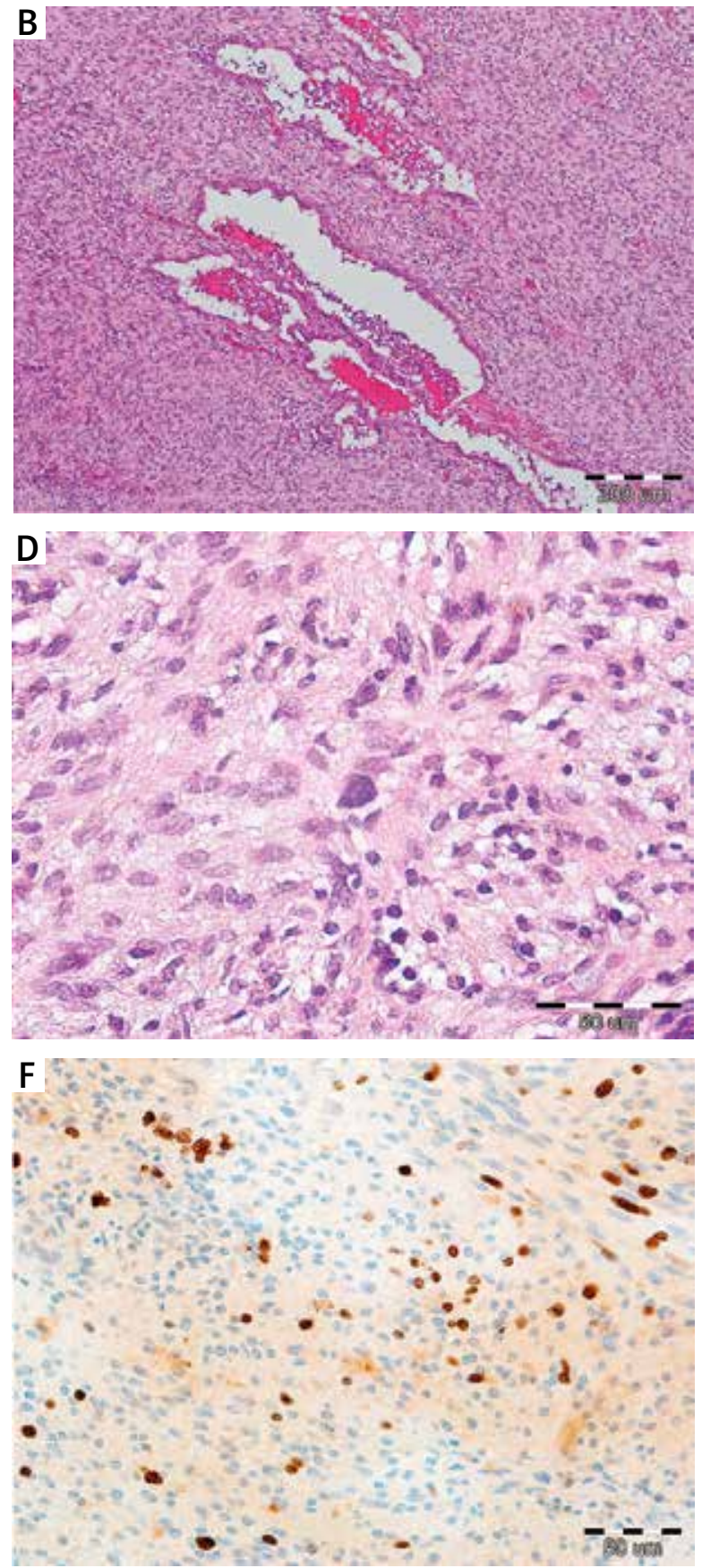

Fig. 8. Histopathological examination results: A) focally palisading nuclei of spindle cells represented by a Verocay body ("Antoni A") (left side of the image) and marked myxoid degeneration area (right side of the image), B) multiple microcyst formation, C) irregular vessels with hyalinized walls, D) marked cellular and nuclear atypia but no mitotic figures, E) immunohistochemical expression of S-100 protein in differentiated Schwann cells, F) proliferative index Ki-67 positive, low (4\%). 
seven patients diagnosed with ancient schwannoma [10]. Ancient schwannoma is a rare degenerative type of schwannoma described for the first time in 1951 by Ackerman and Taylor [1] and accounts for $0.8 \%$ of soft tissue tumours [4,22]. This type of neoplasm occurs predominantly in the form of large, slow-growing tumours located in deep tissue layers of the head, neck, chest, retroperitoneum, pelvis and limbs $[10,18,31,38]$. Ancient schwannoma develops mainly in elderly people [38]. Presence of degenerative changes in this type of tumour is associated with a prolonged period of its growth $[10,38]$. Very rare cases of ancient schwannoma characterised by rapid growth have been described. Isobe et al. in their material comprising 7 patients diagnosed with ancient schwannoma in 2 cases observed a short period of tumour growth lasting one and two years [10]. Lee et al. described a case of ancient schwannoma development in a thigh with very fast increase in tumour size within one year [18]. Likewise, in our 22-year-old female patient development of ancient schwannoma in the superficial radial nerve lasted only 2 years. Lee et al. concluded that long-term clinical history is not essential for ancient schwannoma diagnosis [18]. Ancient schwannoma with degenerative changes including nuclear atypia, hyperchromasia and pleomorphism can be misdiagnosed as sarcoma [17]. According to Klijanienko et al., the principal discriminative morphological differences between well-differentiated malignant peripheral nerve sheath tumour (MPNST) and schwannoma rely on the presence of mitotic figures and the absence of Verocay bodies [17].

In both of the described cases, diagnosis of neurofibromatosis type 1 and 2 was excluded based on clinical examination and additional examinations' results. The patients' families had no history of neurofibromatosis type 1 and 2 or schwannomatosis. Both described cases can be classified as segmental schwannomatosis. Schwannomatosis is a genetic disorder described for the first time in the 1970s and for more than 20 years considered a form of neurofibromatosis [13]. In the late 1990s the suggestion was made that schwannomatosis should be classified as a separate condition [21]. The first clinical diagnostic criteria were formulated in 1997 by Jacoby et al. [12]. Contemporary diagnostic clinical criteria for schwannomatosis were established in 2005 during a meeting under the patronage of the National Neurofibromatosis Foundation [20]. One year later they were made even more precise, and in this form they are valid until today $[2,3]$ - Table I.

Schwannomatosis occurs with an annual incidence estimated at 0.58 cases/ 1000000 persons $[5,20]$. There are two types of schwannomatosis: sporadic and familial [5]. Patients diagnosed with schwannomatosis constitute a small fraction of all patients treated surgically for schwannomas. In material presented by Seppälä et al. patients with schwannomatosis accounted for $3.7 \%$ and in material by Huang for $4.6 \%$ of all patients who underwent operative treatment $[9,28]$. In material presented by Wang et al. 5 cases of segmental schwannomatosis constituted $1.4 \%$ of all treated patients [39]. It is estimated that segmental schwannomatosis constitutes about $30 \%$ of all cases of schwannomatosis [20]. Gonzalvo et al. described 4 cases of the segmental form among 14 patients diagnosed with schwannomatosis. The segmental form was found only in patients with sporadic schwannomatosis [5]. It was similar in our two patients. Medical history and clinical manifestations enabled diagnosis of segmental sporadic schwannomatosis.

\section{Conclusions}

To conclude, we have presented two cases of a rare disorder (segmental schwannomatosis) of an extremely rare location (digital nerves, superficial radial nerve) and histopathological pattern - ancient schwannoma (case 2).

\section{Acknowledgements}

We thank Bartosz Witkowski, who provided medical writing service on behalf of Wroclaw Medical University.

\section{Disclosure}

The authors report no conflict of interest.

\section{References}

1. Ackerman LV, Taylor FH. Neurogenous tumors within the thorax; a clinicopathological evaluation of forty-eight cases. Cancer 1951; 4: 669-691.

2. Baser ME, Friedman JM, Evans DG. Increasing the specificity of diagnostic criteria for schwannomatosis. Neurology 2006; 66: 730-732.

3. Ferner RE. Neurofibromatosis 1 and neurofibromatosis 2: a twenty first century perspective. Lancet Neurol 2007; 6: 340-351.

4. Gillies RM, Burrows C. Nerve sheath ganglion of the superficial radial nerve. J Hand Surg [Br] 1991; 16: 94-95. 
5. Gonzalvo A, Fowler A, Cook RJ, Little NS, Wheeler H, McDonald KL, Biggs MT. Schwannomatosis, sporadic schwannomatosis, and familial schwannomatosis: a surgical series with long-term follow-up. J Neurosurg 2011; 114: 756-762.

6. Gosk J, Rutowski R, Rabczyński J. Peripheral nerve tumours in own material. Folia Neuropathol 2004; 42: 203-207.

7. Gosk J, Zimmer K, Rutowski R. Peripheral nerve tumours - diagnostic and therapeutical basics. Folia Neuropathol 2004; 42: 31-35.

8. Han K-J, Lee YS, Park M. Digital nerve schwannoma of the hand. J Hand Surg [Eur] 2012; 37: 361-362.

9. Huang JH, Simon SL, Nagpal S, Nelson PT, Zager EL. Management of patients with schwannomatosis: report of six cases and review of the literature. Surg Neurol 2004; 62: 353-361.

10. Isobe K, Shimizu T, Akahane T, Kato H. Imaging of ancient schwannoma. AJR Am J Roentgenol 2004; 183: 331-336.

11. Jacob RA, Buchino JJ. Lipofibroma of the superficial branch of the radial nerve. J Hand Surg [Am] 1989; 14: 704-706.

12. Jacoby LB, Jones D, Davis K, Kronn D, Short MP, Gusella J, MacCollin M. Molecular analysis of the NF2 tumor-suppressor gene in schwannomatosis. Am J Hum Genet 1997; 61: 1293-1302.

13. Javalkar VK, Pigott T, Pal P, Findlay G. Multiple schwannomas: report of two cases. Eur Spine J 2007; 16: s287-s292.

14. Joyce M, Laing AJ, Mullet H, Mofidi A, Tansey D, Connolly CE, Mccabe JP. Multiple schwannomas of the posterior tibial nerve. Foot Ankle Surg 2002; 8: 101-103.

15. Kilic A, Cinar C, Arslan H, Pilanci O, Altindas M. Re: A benign schwannoma of the digital nerve distal to the proximal interphalangeal joint. J Hand Surg Eur Vol 2008; 33: 212-213.

16. Kim HS, Kim CH, Kang SG, Tark MS. Compression of the Superficial Radial Nerve by Schwannoma: A Case Report. J Korean Soc Plast Reconstr Surg 2011; 38: 494-497.

17. Klijanienko J, Caillaud JM, Lagacé R. Cytohistologic correlations in schwannomas (neurilemmomas), including "ancient”, cellular, and epithelioid variants. Diagn Cytopathol 2006; 34: 517 522.

18. Lee YS, Kim JO, Park SE. Ancient schwannoma of the thigh mimicking a malignant tumour: a report of two cases, with emphasis on MRI findings. Br J Radiol 2010; 83: e154-e157.

19. Lewkonia P, Medlicott SAC, Hildebrand KA. Intramuscular myxoid lipoma in the proximal forearm presenting as an olecranon mass with superficial radial nerve palsy: a case report. J Med Case Reports 2011; 5: 321-324.

20. MacCollin M, Chiocca EA, Evans DG, Friedman JM, Horvitz R, Jaramillo D, Lev M, Mautner VF, Niimura M, Plotkin SR, Sang CN, Stemmer-Rachamimov A, Roach ES. Diagnostic criteria for schwannomatosis. Neurology 2005; 64: 1838-1845.

21. MacCollin M, Woodfin W, Kronn D, Short MP. Schwannomatosis: a clinical and pathologic study. Neurology 1996; 46: 1072 1079.

22. Malizos K, Ioannou M, Kontogeorgakos V. Ancient schwannoma involving the median nerve: a case report and review of the literature. Strategies Trauma Limb Reconstr 2013; 8: 63-66.

23. Marchant MH Jr, Gambardella RA, Podesta L. Superficial radial nerve injury after avulsion fracture of the brachioradialis muscle origin in a professional lacrosse player: a case report. J Shoulder Elbow Surg 2009; 18: e9-e12.
24. Molina AR, Chatterton BD, Kalson NS, Fallowfield ME, Khandwala AR. Multiple schwannomas of the upper limb related exclusively to the ulnar nerve in a patient with segmental schwannomatosis. J Plast Reconstr Aesthet Surg 2013; 66: e376-e379.

25. Ogose A, Hotta T, Morita T, Otsuka H, Hirata Y. Multiple schwannomas in the peripheral nerves. J Bone Joint Surg Br 1998; 80 : 657-661.

26. Öz O, Yücel M, Ulaş U, Eroğlu E, Odabaşi Z. Superficial radial neuropathy and brachioradial motor nerve palsy associated with proximal radius osteochondroma. Neurol Neurochir Pol 2010; 44: 208-210.

27. Rockwell GM, Thoma A, Salama S. Schwannoma of the hand and wrist. Plast Reconstr Surg 2003; 111: 1227-1232.

28. Seppälä MT, Sainio MA, Haltia MJ, Kinnunen JJ, Setälä KH, Jääskeläinen JE. Multiple schwannomas: schwannomatosis or neurofibromatosis type 2? J Neurosurg 1998; 89: 36-41.

29. Shao X, Zhang X, Su X. Multiple schwannomas of the ulnar nerve. J Plast Surg Hand Surg 2014; 48: 281-282.

30. Stuart JE, Smith AC. Plasmocytoma of the superficial radial nerve. J Hand Surg Am 2001; 26: 776-780.

31. Tadvi JS, Anand A, Humphrey A. Ancient schwannoma of the middle finger. J Hand Surg Eur 2007; 32: 722.

32. Takeuchi A, Yoshida T, Mori H, Tateno M, Satoh H. A case of neurilemmoma on the distal phalanx of the hand. Jap J Plast Reconstr Surg 1999; 52: 145-148.

33. Tanabe K, Tada K, Ninomiya H. Multiple schwannomas in the radial nerve. J Hand Surg Br 1997; 22: 664-666.

34. Tang CY, Fung B, Fok M, Zhu J. Schwannoma in the upper limbs. Biomed Res Int 2013; 2013: 167196.

35. Trăistaru R, Enăchescu V, Manuc D, Gruia C, Ghiluşi M. Multiple right schwannoma. Rom J Morphol Embryol 2008; 49: 235-239.

36. Tzeng CY, Lee TS, Chen IC. Superficial radial nerve compression caused by a parosteal lipoma of proximal radius: a case report. Hand Surg 2005; 10: 293-296.

37. Visser LH. High-resolution sonography of the superficial radial nerve with two case reports. Muscle Nerve 2009; 39: 392-395.

38. Vlychou M, Dailiana ZH. Ancient schwannoma of the hand. J Hand Surg Am 2011; 36: 2030-2033.

39. Wang ZX, Chen SL, Yi CJ, Li C, Rong YB, Tian GL. Segmental schwannomatosis in upper-extremity: 5 cases report and literature review. J Peking University Health Sciences 2013; 45: 698-703.

40. Yoshii S, Ikeda K, Murakami H. Compression neuropathy of the superficial branch of the radial nerve. Scand J Plast Reconstr Surg Hand Surg 2000; 34: 93-95.

41. Zhou J, Man X-Y, Zheng M, Cai S-Q. Multiple plexiform schwannoma of a finger. Eur J Dermatol 2012; 22: 149-150. 